\title{
Prediction of Stature in Males of Tamil Population from Measurements of Percutaneous Tibial Length
}

\author{
M. Sreenivasan ${ }^{1}$, S.K. Nawaz Ahmed ${ }^{2}$ \\ ${ }^{1}$ Professor, Department of Forensic Medicine, Chettinad Hospital and Research Institute, Chettinad Academy \\ of Research and Education (CARE), Kelambakkam, Tamil Nadu, ${ }^{2}$ Professor, Department of Forensic Medicine, \\ Chettinad Hospital and Research Institute, Chettinad Academy of Research and Education (CARE), Kelambakkam, \\ Tamil Nadu
}

\begin{abstract}
Forensic experts are often in confrontation with the challenging task of determination of stature along with race, age etc. for the purpose of establishing the identity of the deceased individual in those circumstances where only skeletal remains, mutilated or dismembered body parts, extremely decomposed body parts etc. are provided by investigating authorities. In the current study, a genuine attempt has been made to arrive at the population specific regression equation for stature prediction from the percutaneous length of Tibia. The subjects chosen for this study include 120 adult males belonging to Tamil population falling within the age range of 21 to 30 years. Stature and percutaneous lengths of right and left Tibia from each subject were precisely recorded following standard protocols using appropriate instruments and analysis of the data collected was done applying Pearson correlation through SPSS software version 26 to arrive at the regression equations for stature assessment based on percutaneous right and left Tibial lengths respectively. By comparing the regression formulae obtained from the present study with those derived from various population specific studies done on Indian population, our regression equations found to be distinctive to Tamil population and therefore can be authentically applied for calculation of stature of deceased from percutaneous Tibial length in males of Tamil population whenever skeletal remains are available.
\end{abstract}

Keywords: Stature, Tibial length, Regression equation, Males, Tamil population.

\section{Introduction}

One of the significant parameters for establishment of individuality of a person is the determination of stature from the length of long bones. In those circumstances where dismembered, putrefied human body parts or skeletal remains are available, Anatomical method $^{1}$ may be adopted for prediction of stature of the deceased if entire skeleton is provided for examination or by applying Mathematical method where taking measurement of length of a particular long bone may

\section{Corresponding Author:}

\section{Dr. S.K. Nawaz Ahmed}

Professor, Department of Forensic Medicine, Chettinad Hospital and Research Institute, Chettinad Academy of Research and Education (CARE), Rajiv Gandhi Salai, Kelambakkam, 603103, Tamil Nadu, India e-mail: snawazahmed2010@gmail.com help the purpose as there exists a firm relationship between stature and skeletal element. Commonly Mathematical estimates of height are derived by means of application of a single general regression formula that is population specific. The most reliable estimates have been derived by employing regression formulae based on length of long bones, especially those of lower limb. Nevertheless, it is clearly known that a regression equation that is formulated for one particular population does not automatically yield dependable results for another. $^{2}$

After Femur, Tibial length measurement provides more reliable estimation of height than any other long bone. This is because of the fact that Tibia can be readily accessible for length assessment which is responsible for $22 \%$ of stature. ${ }^{3,4}$ Similarly, percutaneous measurement of length of Tibia in the living gives high degree of accuracy for stature prediction. ${ }^{5}$ In addition, Tibia plays a vital role in anthropological research as it resists 
disintegration and thereby retaining its morphology long after death. ${ }^{6-9}$

For stature determination from long bones, Trotter and Gleser regression formula has been frequently used. As population specific regression equations specific to Tamil population are negligible, we did the detailed study and derivation of regression formula pertaining to males of Tamil population. Different parameters gained in the current study were put into comparison with those derived by similar research studies done on various population groups in India and found to have definite statistical significance.

\section{Materials and Method}

The participants chosen for this study included 120 adult males in the age group 21 to 30 years belonging to Tamil population. The procedure, aims and objectives of the present study were clearly explained to every subject and written informed consent obtained with signature. The subjects with skeletal abnormalities involving limb, foot or spine were carefully exempted as participants of the study. To exclude possible diurnal height variation, all stature data were collected during morning hours i.e. 9 am to 11 am and to avoid any inter-observer variation, same investigator involved in taking all measurements.

Stature measurement was taken while participant standing upright on base platform of stadiometer with head held in Frankfort horizontal eye-ear plane by supporting subject's chin and living stature estimated as the distance between heel and utmost point on vertex of the head with accuracy of $0.1 \mathrm{~cm}$.

For measurement of right and left percutaneous Tibial length (PCTL), standardized and commonly applied protocol ${ }^{10}$ and techniques ${ }^{11-14}$ were followed. The spreading caliper with accuracy of measuring up to $0.1 \mathrm{~cm}$. was used and degree of arms separation of caliper was determined from its steel tape. The participant was made to sit facing the examiner in a position keeping his ankle of the measurement side relaxing on the opposite side knee exposing medial side of Tibia upwards so that Tibiale point is easily accessible. Percutaneous Tibial length is determined as the maximum distance between Tibiale, the highest point on medial condyle along its medial border and Spherion, the distal most point on medial malleolus ${ }^{15}$ after marking these two Tibial landmarks with skin marking pencil. The recorded stature and Tibial length data from all subjects were carefully analyzed using the latest SPSS software version 26 and the statistical results such as Mean, Standard deviation, Correlation coefficient and linear regression equation for stature estimation.

\section{Results}

Various statistical parameters derived based on the analysis of stature and length of either side Tibia were tabulated (Table 1) for comparative interpretation. The determined mean lengths of left and right Tibia were $37.59 \mathrm{~cm}$. (Standard deviation of $1.18 \mathrm{~cm}$.) and 37.62 $\mathrm{cm}$. (Standard deviation of $1.16 \mathrm{~cm}$.) respectively. The estimated mean stature of participants was $170.5 \mathrm{~cm}$. (Standard deviation of $3.9 \mathrm{~cm}$.). Pearson's Correlation coefficient ( $r$ ) for height to left Tibial length was 0.757 $(\mathrm{p}<0.001)$ with Regression coefficient (b) of 2.51 $(p<0.001)$. Similarly, the Correlation coefficient $(r)$ pertaining to right Tibial length was $0.741 \quad(p<0.001)$ with corresponding Regression coefficient (b) of 2.5 $(\mathrm{p}<0.001)$.

Table 1: Significant statistical parameters for Right and Left Tibia in Males

\begin{tabular}{|l|c|c|}
\hline Parameter & \multicolumn{2}{|c|}{ Dependent Variable } \\
\hline Mean Stature $(\mathrm{cm})$. & \multicolumn{2}{|c|}{170.5} \\
\hline & \multicolumn{2}{|c|}{ Independent Variable } \\
\hline & Right PCTL $(\mathrm{cm})$. & Left PCTL $(\mathrm{cm})$. \\
\hline Mean Length $(\mathrm{cm})$. & 37.6208 & 37.5973 \\
\hline Standard Deviation & 1.161 & $0.757[\mathrm{p}<0.001]$ \\
\hline Correlation Coefficient $(\mathrm{r})$ & $0.741[\mathrm{p}<0.001]$ & 0.573 \\
\hline Coefficient of Determination $\left(\mathrm{R}^{2}\right)$ & 0.550 & 76.111 \\
\hline Regression Constant & 76.440 & 2.51 \\
\hline Regression Coefficient $(\mathrm{b})$ & 2.5 & 2.5639 \\
\hline Standard Error of Estimate & 2.6380 & \\
\hline
\end{tabular}


Table 2: Regression equation for Stature estimation from PCTL in Males

\begin{tabular}{|l|l|}
\hline PCTL & Regression equation for Stature \\
\hline Right PCTL $(\mathrm{cm})$. & $\mathrm{y}_{1}=2.5 \times$ Right PCTL $(\mathrm{cm})+76.440$. \\
\hline Left PCTL $(\mathrm{cm})$. & $\mathrm{y}_{2}=2.51 \times$ Left PCTL $(\mathrm{cm})+76.111$. \\
\hline
\end{tabular}

Fig. 1 and 2 are scatter diagrams prepared by means of plotting the stature data against those right and left Tibia from subjects and Table 2 shows the linear regression equations for determination of stature with respect to each side Tibia.

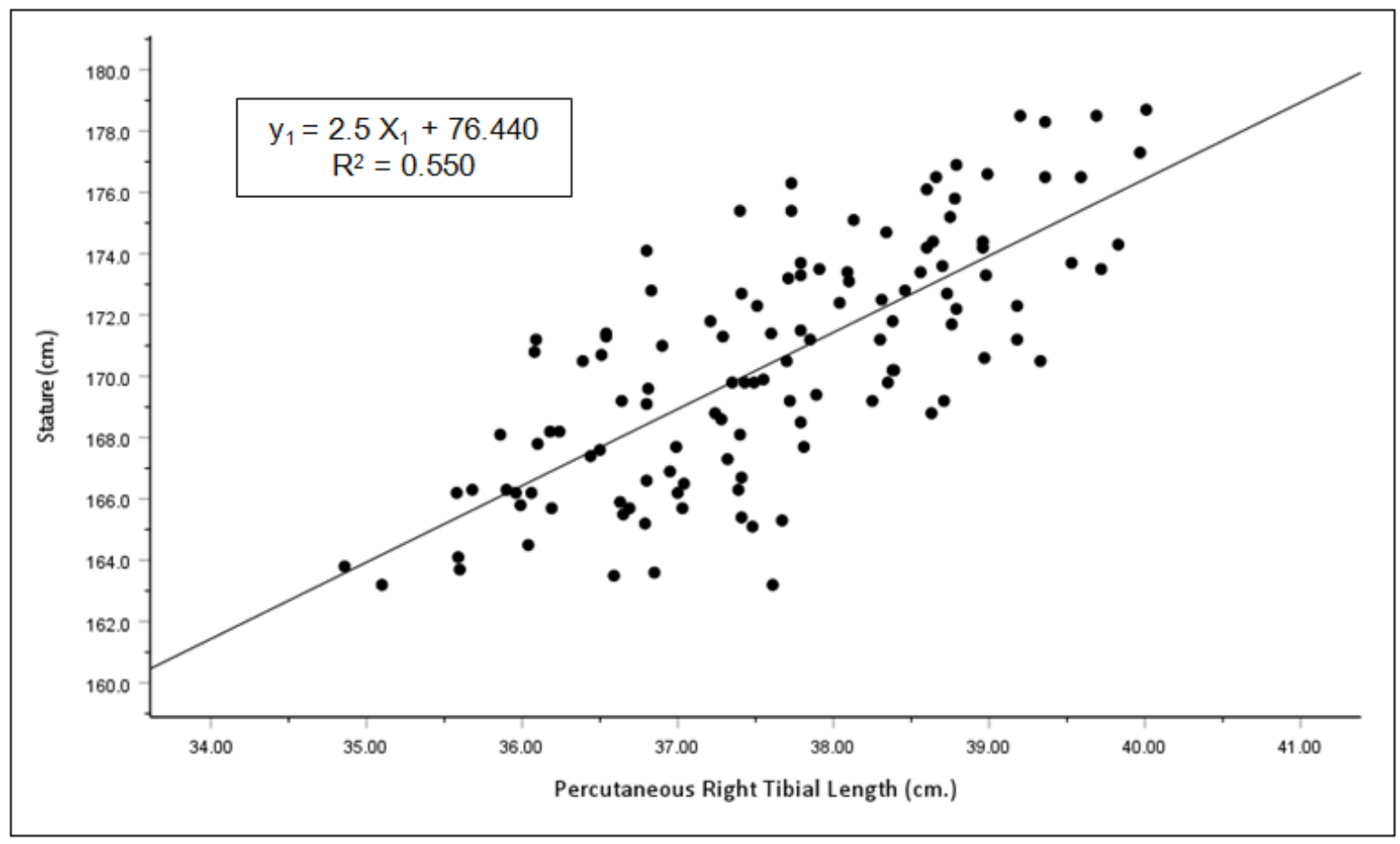

Fig. 1: Correlation between Right PCTL $\left(X_{1}\right)$ and Stature $\left(y_{1}\right)$ in Males

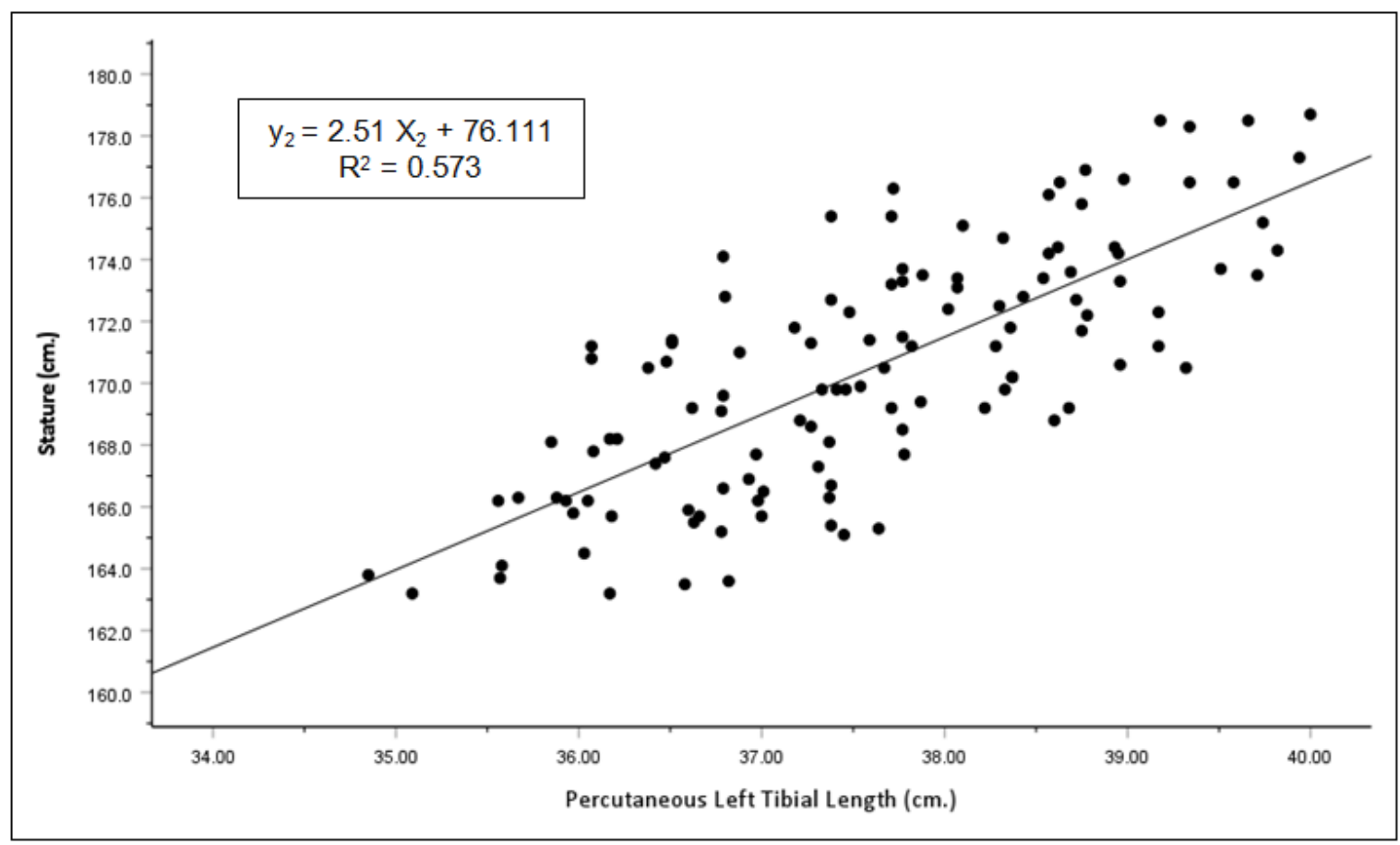

Fig. 2: Correlation between Left PCTL $\left(X_{2}\right)$ and Stature $\left(y_{2}\right)$ in Males 


\section{Discussion}

Anthropometric measurements are generally applied for the assessment of stature of a deceased person for establishing the identification in medicolegal circumstances. Then regression formula derived from a particular population study cannot be applied for stature calculation for all population types which necessitates various baseline data have to be derived from different ethnic populations leading to more accurate equations that can be reliably applied for the stature assessment amongst them. Regression analysis leads to the derivation of formula for stature assessment that can provide $95 \%$ confidence intervals with respect to estimation of stature. The similar stature assessment techniques were advocated by different authors. ${ }^{16-20}$

Since the actual stature of victims is commonly unknown in most of forensic cases, we did the present study focusing on this challenging problem. Therefore, we have attempted to establish the particular population specific stature formulae based on lengths of right and left Tibia. The data derived from the present investigation indicates that population specific stature regression formulae provide more reliable and accurate estimates than those from general formulae.

The derivation of stature needs special attention in those cases where corpses are found in extremely decomposed, mutilated state or only fragmentary remains of skeleton are available. The present study was done on living adult male subjects belonging to Tamil population to correlate body height with percutaneous tibial length in various ethnic populations. Simple population specific linear regression formulae for stature corresponding to right and left Tibia were derived that can be applied for determination of stature.

It is obvious from Table 3 that minor variations pertaining to mean right and left percutaneous Tibial lengths and mean height when these data are compared in different ethnic populations in India and these variations may very well be assumed as the result of multiple factors affecting a person's growth and body proportions viz. dietary habits affecting nutritional status, heredity, physical stress modifying life style, environmental conditions, geographical factors etc. If we assume these minor variations with respect to stature and PCTL existing in different populations are the result of above-mentioned influencing factors, then the results will remain unchanged when statistical studies done in various populations at any given point of time due to the fact that those influencing factors do not lead to different modifications in different populations. Nevertheless, if such variations in results are presumed to be due to influencing factors of plastic ones like lifestyle, physical stress, nutritional status etc. then we can safely propose that the different anthropometric data as reference standards should be measured, recorded and analyzed periodically at constant time intervals in every population so that the results can very well be employed with high accuracy and reliability.

Table 3: Comparison of Mean Stature and Mean Tibial length in Males

\begin{tabular}{|c|c|c|c|c|c|}
\hline \multirow{2}{*}{$\begin{array}{l}\text { Name of the } \\
\text { Researcher }\end{array}$} & \multirow{2}{*}{ Year } & \multirow{2}{*}{$\begin{array}{c}\text { Population for } \\
\text { study }\end{array}$} & \multirow{2}{*}{$\begin{array}{c}\text { Mean Stature } \\
(\mathrm{cm} .)\end{array}$} & \multicolumn{2}{|c|}{ Mean Tibial length (cm.) } \\
\hline & & & & Right & Left \\
\hline Present Study & 2020 & Tamil Nadu & 170.5 & 37.6208 & 37.5973 \\
\hline Kavyashree $\mathrm{AN}^{21}$ & 2018 & Karnataka & 170.88 & 38.52 & 38.56 \\
\hline Anitha $\mathrm{MR}^{22}$ & 2016 & South India & 161.93 & 37.43 & 37.50 \\
\hline Prerna Gupta ${ }^{13}$ & 2014 & Uttar Pradesh & 168.56 & 37.23 & 37.33 \\
\hline Akhilesh Trivedi ${ }^{23}$ & 2014 & Madhya Pradesh & 164.5 & 38.26 & 38.22 \\
\hline Ashita Kaore 24 & 2012 & Karnataka & 170.08 & 35.77 & 35.73 \\
\hline
\end{tabular}


Table 4: Comparison of Regression Formula for Stature $(y)$ in Males from length of Right Tibia $\left(X_{1}\right)$ and Left Tibia $\left(\mathbf{X}_{2}\right)$

\begin{tabular}{|c|c|c|c|c|}
\hline \multirow{2}{*}{ Name of the Researcher } & \multirow{2}{*}{ Year } & \multirow{2}{*}{ Population for study } & \multicolumn{2}{|c|}{ Regression formula } \\
\hline & & & Right Tibia & Left Tibia \\
\hline Present Study & 2020 & Tamil Nadu & $Y_{1}=2.5 X_{1}+76.44$ & $\mathrm{Y}_{2}=2.51 \mathrm{X}_{2}+76.11$ \\
\hline Kavyashree $\mathrm{AN}^{21}$ & 2018 & Karnataka & $Y_{1}=1.52 X_{1}+112.20$ & $Y_{2}=1.56 X_{2}+110.56$ \\
\hline Anitha $\mathrm{MR}^{22}$ & 2016 & South India & $Y_{1}=1.8 X_{1}+94.5$ & $\mathrm{Y}_{2}=1.95 \mathrm{X}_{2}+88.55$ \\
\hline Prerna Gupta ${ }^{13}$ & 2014 & Uttar Pradesh & $\mathrm{Y}_{1}=2.37 \mathrm{X}_{1}+80.03$ & $\mathrm{Y}_{2}=2.39 \mathrm{X}_{2}+79.26$ \\
\hline Akhilesh Trivedi $^{23}$ & 2014 & Madhya Pradesh & $Y_{1}=1.40 X_{1}+110.76$ & $\mathrm{Y}_{2}=1.59 \mathrm{X}_{2}+103.71$ \\
\hline Ashita Kaore ${ }^{24}$ & 2012 & Karnataka & $Y_{1}=1.84 X_{1}+104.42$ & $\mathrm{Y}_{2}=1.85 \mathrm{X}_{2}+104.08$ \\
\hline
\end{tabular}

On comparison of different regression equations for stature prediction derived from various ethnic populations of our country, as shown in above Table 4, we can very well presume that all these investigators have made out the existence of obvious positive correlation between percutaneous right and left Tibial lengths and stature which clearly proves that there remains a stronger and reliable relationship between person's height and Tibial length.

\section{Conclusion}

The derived regression equations for stature assessment have been found to be fairly accurate for males belonging to Tamil population based on the fact that estimated stature were within the range of error and found to be in close approximation with that of the observed stature and therefore the derived regression equations for stature assessment for males based on percutaneous length of Tibia in males belonging to Tamil population and can be employed with authentication whenever the determination of height of deceased person arises with respect to highly putrefied bodies, skeletons, dismembered limbs are available for the establishment of identity of deceased which in turn leads to the establishment of corpus delicti i.e. facts suggestive of criminal offence where personal identification is one of the significant fact. Based on the results of the present study, we highly recommend that several similar studies among Tamil population involving different age groups to arrive at the specific regression formulae which will be of immense help to forensic experts and anthropologists for population specific stature estimation and subsequent establishment of identity of individual in mass disasters and other above mentioned challenging forensic circumstances.
Conflict of Interest: None declared.

Source of Funding: Nil.

Informed Consent: Obtained from all subjects.

Ethical Clearance: Necessary ethical approval was obtained from the Institutional Ethics Committee, Chettinad Academy of Research and Education (CARE), Kelambakkam - 603103.

\section{References}

1. Lundy JK. The mathematical versus anatomical method of stature estimate from long bones. Am J Forensic Med Pathol. 1985;6(1):73-6.

2. Krogman WM, Iscan MY. The Human Skeleton in Forensic Medicine. Charles C. Thomas, Springfield, Illinois. 1986;302-51.

3. Dikshit PC. HWV Cox Medical jurisprudence and Toxicology. $7^{\text {th }}$ ed. LexisNexis Butterworths, India. 2002.

4. Alka DS, Sharad DA: Estimation of stature from percutaneous measurement of Tibia in living. Medico-Legal Update. 2013;13(2):5-7.

5. Akhlaghi M, Sheikhazadi A, Khosravi N et al. The value of the anthropometric parameters of the Tibia in the forensic identification of the Iranian population over the age of 20. J Forensic Leg Med. 2011;18:257-63.

6. Rhine S. Non-metric skull racing. In: Gill GW, Rhine S, eds. Skeletal Attribution of Race: Method for Forensic Anthropology. Albuquerque, NM: Maxwell Museum of Anthropology; 1990;9-20.

7. Williams PL, Warwick R, Dyson M et al. Skeletal System. In: Gray's Anatomy, $37^{\text {th }}$ 
ed. Churchill Livingstone, London. 1995;601-12.

8. Kirici Y, Ozan H. Determination of sex from the Tibia of adult Turkish cadavers. Kaibogaku Zasshi. J Anat. 1999;74(5):537-43.

9. Antonova E, Le TK, Burge R et al. Tibia shaft fractures: Costly burden of nonunions. BMC Musculoskelet Disord. 2013;14(42):1-10.

10. Lohman TG, Roche AF, Martorell R, eds. Anthropometric Standardization Reference Manual. Human Kinetics Books, Champaign, IL. 1988.

11. Chavan SK, Chavan KD, Mumbre SS et al. Stature and Percutaneous Tibial Length: A Correlational Study in Maharashtrian Population. Indian $\mathrm{J}$ Forensic Med Pathol. 2009;2(3):109-12.

12. Duyar I, Pelin C. Body Height Estimation Based on Tibia Length in Different Stature Groups. Am J Phys Anthropol. 2003;122:23-7.

13. Gupta P, Kumar P, Gaharwar A et al. Correlation of Percutaneous Length of Tibia with Body Height and Estimation of Stature in Living North Indian Males. Sch J App Med Sci. 2014;2(2D):848-52.

14. Mehta AA, Mehta AA, Gajbhiye VM et al. Correlation of percutaneous Tibial length with body height and estimation of stature in living Central India population. Int J Anat Res. 2015;3(2):115961.

15. Martin R, Saller K. Lehrbuch der Anthropologie in Systematischer Darstellung. Fischer Stuttgart. 1957;1(3).
16. Sanli SG, Kizilkanat ED, Boyan N et al. Stature estimation based on hand length and foot length. Clin Anat 2005;18(8):589-96.

17. Agnihotri AK, Purwar B, Googoolye $\mathrm{K}$ et al. Estimation of stature by foot length. J. Forensic Legal Med. 2007;14(5):279-83.

18. Ozden H, Balci Y, Demrustu C et al. Stature and sex estimate using foot and shoe dimensions. Forensic Sci Int. 2005;147(2-3):181-4.

19. Gordon CC, Buikstra JE: Linear models for prediction of stature from foot and boot dimensions. J Forensic Sci. 1992;37(3):771-82.

20. Mondal MK, Jana TK, Das J et al. Use of length of Ulna for estimation of stature in living adult male in Burdwan District and adjacent areas of West Bengal. J Anat Soc India. 2009;58(1):16-18.

21. Kavyashree AN, Bindurani MK, Asha KR et al. Estimation of stature by morphometry of percutaneous Tibia. Ind $\mathrm{J}$ Clin Anat Physiol. 2018;5(3):308-13.

22. Anita MR, Bharathi D, Rajitha V et al. Estimation of height from percutaneous Tibial length among South Indian population. Ind J Clin Anat Physiol. 2016;3(4):405-7.

23. Trivedi A, Saxena S, Morya R. et al. Stature estimation using percutaneous Tibial length in people of Gwalior region. J Dent Med Sci. 2014;13(5):65-70.

24. Kaore A, Kaore BP, Kamdi A et al. Stature estimation from Tibial length. Natl J Integr Res Med. 2012;3(2):51-6. 